\title{
CONCURRENTLY PART-MACHINE GROUPS FORMATION WITH IMPORTANT PRODUCTION DATA
}

\author{
Lokesh, K.* \& Jain, P. K.* \\ * Department of Mechanical Engineering, J.M.I., Delhi-110025, India \\ ${ }^{* *}$ Department of Mechanical and Industrial Engineering, I.I.T., Roorkee, India \\ E-Mail: lokeshkrsax@rediffmail.com,pkjain123@gmail.com
}

\begin{abstract}
This work presents an algorithm for design of cellular manufacturing system. It considers sequence of operation for every component as ordinal level data. The ratio level data includes operation time per unit, production volume and machine capacity. A matrix model is developed to incorporate ordinal level data and ratio level data. Model is then standardized. From this, Part - Part correlation model is formed. This is undergone through principle component analysis. Now, Feature-Vector and New Standardized Sequence Part Load matrices are formed. These are used for grouping purpose. Part-machine orthographic view is used for concurrent part-machine family formation. Performance of algorithm is comparable and of good quality with existing methods in its class. To facilitate industrial application, it can be implemented by using free software, Scilab and/or commercial softwares.

(Received in November 2008, accepted in June 2009. This paper was with the authors 1 month for 1 revision.)
\end{abstract}

Key Words: Cellular Manufacturing, Part-Machine Families, Algorithm

\section{INTRODUCTION}

Cellular manufacturing (CM) is an applied concept of group technology and Just-in-time. It changes the conventional practice of manufacturing from functional production into small to medium-sized batch oriented production. The reported advantages of CM are such as better management of labour, tooling and production time, reduction of space, work in process inventory as well as paper work etc.

The basic problem in the design of cellular manufacturing system lies in the identification and grouping of parts that share similar process into families and their associate machines into cells, the ideal CM solution is to ensure all parts in a family fully processed within a cell. Parts that are manufactured by more then one cell are known as exceptional parts. There should be a minimum number of parts requiring intercell travel.

\section{LITERATURE REVIEW}

Techniques to develop possible solution are plentiful in the literature. These techniques can be classified into machine-part grouping approaches, the machine grouping approaches and the part grouping approaches. The machine-part grouping approach consists of the simultaneous identification of machine cells and part families, the part grouping approach attempts the initial formation of part families and followed by assignment of machines to those families. The machine grouping approaches are based on first identification of machine cells and then assign parts to those machines.

The main theme throughout the most research papers is clustering the unit valued (i.e. binary 0 or 1) entries of part-machine incidence matrix alone [1-11]. Many researchers considered similarities coefficients based approaches to solve cell formation (CF) problem. 
Similarity coefficients methods are found more flexible than other CF approaches [12]. An approach, average voids value $(A V V)$ is proposed which indicates the average number of newly produced voids, when a pair of machine groups is combined [13].

Some parts can not be processed in a cell. These parts need intercell travel for further operations. Different order sequence of machine may result in different total intercellular movement distance unit. When production volume is large, total number of intercell movements will be further large. Part-machine grouping without considering operation sequences also tends to distort the real extent of material handling efforts within and outside the cells [6, 14-17]. Nair and Narendran proposed CASE (1998) - SCM based model [15] using sequence data only and Accord (1999) - SCM based model [16] using ordinal and ratio level data. They emphasized use of operation sequence, operation time, production volume and machine capacity for grouping. George et al. [14] proposed an interactive cluster approach, a SCM based model considering ordinal and ratio level data. However, they [14, 16] considered unity production volume in their models. In the design of cellular manufacturing systems, many production factors should be involved when the cells are created, e.g. operation sequences, part production volume and machine capacity [18].

Despite a large number of papers on cell formation being published, only a handful incorporate operation sequence in intercell movement calculations and consider production volume [19]. Many studies only considered limited information, ignoring other important factors, such as operation sequence, machine capacity, and part demand, need to be incorporated to obtain more realistic results [20,21]. Genetic algorithm approach is used by researchers [19, 20]. Fuzzy ART neural network algorithm is also used [17, 21]. Among many methods utilized in machine cells formation, the similarity coefficient method is most widely used. Production sequence and product volumes, if incorporated properly in determining the machine cells, can enhance the quality of solutions and reduce the number of intercellular movements [22]. Alhourani and Seifoddini [22] have considered ordinal level data that is machine sequence and ratio level data as production volume in their SCM model. However, they did not consider other important shop floor realities that are operation time and machine capacity in the SCM model.

Another practical problem faced by the methods developed so far is the fact that most of them have been demonstrated for relatively small data sets. Miltenburg and Montazemi [23] described computational problems encountered with traditional algorithms in an industrial context involving 5498 part types. To cluster data sets of such sizes, a smaller part population had to be selected intuitively, and portions of the problem had to be 'swapped' into memory as they were needed for the computations. There are about 3000 parts processed at Harnischfeger Plant in Oak Creek, Wisconsin [24]. Similar reservations about the limited applicability of traditional procedures for industry-size data sets have been voiced by others [6]. This is serious limitation for difficult and complex techniques such as neural network, simulated annealing, genetic algorithms and tabu search, etc.

Principal component analysis is employed for evaluating the feasibility of CM without initial part matrix clustering [3]. Albadawi et al. [2] proposed factor analysis based clustering approach. Matrix based multivariate analysis model [8] is used to find eigenvalues and eigenvector for grouping. However, all these [2, 3, 8] do not consider sequence, operation time, production volume and machine capacity. Lokesh Kumar [25] proposed an algorithm with operation sequence, operation time and production volume using principal components analysis. However, he did not consider machine capacity.

Further, most of existing methods require a prior specification of the upper limit on number of machine within a cell and or the number of cells. This contradicts the fundamental philosophy of GT that groups exist naturally and the task of analysis is to identify them if they exist [9, 26]. Moreover, there is a limited industrial application due to unavailability of 
software programme supporting solution approaches of CF problem or the software is expensive [27].

Now, one can conclude that a few of existing approaches are designed to accommodate realistic shop conditions such as operation sequence, operation time, production volume and machine capacity all together in a simple user friendly model and to be able to form part families and machine groups simultaneously. This paper presents an algorithm APMOSTVC. APMOSTVC stands for an Algorithm for Concurrent Part families and Machine groups formation with Operation Sequence, operation Time, production Volume and machine Capacity.

\section{APMOSTVC- METHODOLOGY OF PART-MACHINE GROUP FORMATION}

In this section, we describe methodology of algorithm APMOSTVC for formation of part families and machine groups. It is as follows:

\subsection{Mathematical representation of machine - part}

Here, parts are treated as objects and machines as attributes of that part. The requirement of part is represented in the form of object-attribute (i.e. part-machine) matrix.

Columns and rows of matrix represent part and machine, respectively. This matrix is named as Machine Sequence Part Matrix, MSPM. Representations of various matrices are as follows:

- Machine Sequence part Matrix (MSPM) representation:

$\operatorname{MSPM}(I, J)$ element value is 1 , if part $J$ visit first in sequence to machine $I$, this value is 2 , it part $J$ visit second in sequence to machine $I$. This value is 3 , if part $J$ visit third in sequence to machine $I$. And so on.

- Machine Part Operation time Matrix (MPOTM) representation:

In MSPM matrix replace sequence number with processing time of part-machine combination i.e. MPOTM(I, $J)$ represent processing time of part $I$ on machine $J$.

- Production Volume Matrix (PV) representation:

Now, represent production volume of part as matrix $P V . P V(1, J)$ represents production volume of $J^{\text {th }}$ part.

- Machine Capacity (MC) representation: $M C(I, 1)$ element represent machine capacity of $I^{\text {th }}$ machine.

- Set-up time (Setime) matrix representation:

Here, we represent set-up time. Setime $(I, J)$ represents set-up time of part $J$ on machine $I$. In the same manner other idle time can be taken.

\subsection{Part load matrix representation}

Now, ratio level data (i.e. operation time, production volume and machine capacity) is represented as part load matrix (PLM) as follows:

(1) If operation time is available only. $\operatorname{PLM}(I, J)=\operatorname{MPOTM}(I, J)$

(2) If operation time and production volume is available only.

$$
\operatorname{PLM}(I, J)=\operatorname{MPOTM}(I, J) \times P V(1, J)
$$

(3) If operation time, production volume and machine capacity is available,

$$
P L M(I, J)=\operatorname{MPOTM}(I, J) \times P V(1, J) / M C(I, 1)
$$




\subsection{Integration of ordinal level (i.e. sequence) and ratio level data}

Further, ordinal level and ratio level data has to be integrated. Physical significance of operation can be visualized as flow of material or parts. Operation sequence has an impact on flow of material handling. Material handling is aimed to be smooth and minimum. Ratio level data influences within-cell-load variation. Within-cell-load variation is desirable to be minimum. Inter-cell travel is zero, if all parts and machines are in one cell, but the withincell- load variation is maximum. In contrast, when one cell has one machine type, the withinin-cell load variation is zero, but intercell travel is maximum. These are contradictory factors. One has to take trade off. Therefore, Nash [28] principal of bargain should be used. This approach is used by Nair and Narendran [16] and George et al. [14]. From this discussion, we conclude the integration of ordinal level data and ratio level data by a matrix, Sequence Part Load Matrix, SPLM. Element SPLM(I, $J)$ is given as:

$$
\operatorname{SPLM}(I, J)=\operatorname{MSPM}(I, J) \times P L M(I, J)
$$

\subsection{Machine - part analysis and grouping approach}

In part-machine grouping, a large number of variable (i.e. parts and machines are to be reduced into small number of part families and machine groups. In other words, this problem need dimension reduction on the basis of some similarity measures or coefficients. This is achieved as follows:

I. Standardized Sequence Part load Matrix (SSPLM) creation:

Sequence Part Load Matrix, (SPLM) is to be standardized to form standardized sequence part load matrix (SSPLM) by using relation [29, 30]:

$$
\operatorname{SSPLM}(I, J)=\frac{\operatorname{SPLM}(I, J)-\operatorname{SPLM}(J)}{\operatorname{SD}(J)}
$$

Where, $\operatorname{SPLM}(J)$ is the mean of elements of $J^{\text {th }}$ column of matrix $\operatorname{SPLM}(I, J)$,

$S D(J)$ is standard deviation of elements of $J^{\text {th }}$ column of matrix $\operatorname{SPLM}(I, J)$.

II. Part-Part Correlation Matrix (PPCM) Creation:

Now Part-Part Correlation matrix, PPCM is formed from matrix SSPLM by using similarity coefficient [31]. It is given as:

Element $\operatorname{PPCM}(I, J)=1$, if $I=J$,

Otherwise, $\operatorname{PPCM}(I, J)=\frac{1}{m} \sum_{k=1}^{m}[\operatorname{SSPLM}(K, I) \times \operatorname{SSPLM}(K, J)]$

Where: $m=$ number of machines. This matrix indicates similarity between parts.

III. Machine-part dimension reduction:

Now, next logical step is to reduce large number of variables (machine parts) into small set of factors. Principle component analysis transforms a given set of interrelated variables into a new set of variables (i.e. principle components). The principle components are in correlated linear combinations of original variables and account for total variance of original data. The principle component is the best summary of linear relationship among existing original data. The second component is second best and so on. This property enables to separate data into district clusters when projected into a space by first few principle components. This approach can be studied by literature [29, 30, 32, 33]. Now, we consider parts as original set of variables and correlation matrix, PPCM showing the correlation between each pair of parts. In PCA method, principle components are extracted by finding eigen vectors and eigen values for equation: $\operatorname{det}\left(P P C M-\lambda(J) \cdot I_{m}\right)=0 ; J \in(1, p)$ where $I_{m}$ is identity matrix. 
$\lambda(J) \in\left(\lambda_{1} \geq \lambda_{2}, \ldots \lambda_{\mathrm{p}}\right)$ are eigen values (real and non-negative).

$\left\{F_{1}, F_{2}, \ldots F_{\mathrm{p}}\right\}$ are corresponding eigen vectors of matrix PPCM. Eigen vector and eigen values are determined by standard method of matrix algebra. The eigen vector with highest eigen value is the first principle component, second principle component for second highest eigen value and so on.

Each rows of PCA matrix, represent a point in multidimensional space (no. of axis/ dimensions equal to no. of principle components). The line joining this point and origin of coordinate system is a vector (also that part). Orthographic projection of this vector in space on a plane of projection made of first and second principle components represents that part. This projected view is used for grouping purpose. Readers are advised to refer paper [25] for detailed description.

IV. Feature Vector Creation:

To be precise, if you originally have a $p$ dimensional data, you got eigen vectors and eigen values, choose only first $p_{s}$ eigen vectors, then final data set has only $p_{s}$ dimensions. The next step is to form a feature vector. This is formed by taking few or all eigen vectors in descending order of eigen values [34, 35].

$$
\text { Feature-Vector }=\left(F_{1}, F_{2}\right)
$$

$F_{1}$ and $F_{2}$ are first and second principle components of a part, respectively.

V. New standardized sequence Part Load Matrix (NSSPLM) Creation:

Now, new standardized sequence Part Load Matrix (NSSPLM) is created. It is given by relation [34, 35]:

$$
\text { NSSPLM }=\text { Feature-Vector }{ }^{T} \times \text { SSPLM }{ }^{T}
$$

$S S P L M^{T}$ and Feature-Vector ${ }^{T}$ are Transpose of matrix SSPLM and Feature-Vector respectively. Elements of NSSPLM represent original data (SSPLM) solely in terms of chosen eigen vectors (i.e. principle components or feature vector). Basically, we have transformed our data so that it is expressed in terms of the patterns between them. Each rows of NSSPLM matrix, represent a point in multidimensional space (no. of axis/ dimension equal to no. of principle components). The line joining this point and origin of coordinate system is a vector (also a machine). Orthographic projection of this vector in space on a plane of projection made of first and second principle components represents that machine. This projected view is used for grouping purpose. Readers are advised to refer paper [25] for detailed description.

VI. Machine-Part Orthographic View grouping:

Next step is to group machine and parts. It is done by machine-part orthographic view grouping analysis. The main objective of a PCA is to reduce the dimensionality of a set of data. This is particularly advantageous if a set of data with many variables lies, in reality, close to a two-dimensional subspace (plane). In this case the data can be plotted with respect to these two dimensions, thus giving a straightforward visual representation of what the data look like, instead of appearing as a large mass of numbers to be digested. Biplots similarly provide plots of the $m$ observations, but simultaneously they give plots of the relative positions of the $p$ variables in two dimensions. Furthermore, superimposing the two types of plots provides additional information about relationships between variables and observations that is not available in either individual plot [33].

Represent X-axis, Y-axis as first principle components (i.e. first eigen vector) and second principle components (i.e. second eigen vector), respectively. Plot each variable (i.e. parts) with coordinates as (principle component ${ }_{1}$, principle component 2 ). Join this point with zero of coordinates system with a line. This line represents that part. Plot also each attribute (i.e. machine) with coordinates (NSSPLM column 1, NSSPLM column 2). Joint this point with zero of coordinate system with a dotted line. This dotted line represents that machine. Thus, all parts and machines are represented by firms/dotted lines, respectively. This plot is named as 
Machine-Part Orthographic View. Parts with almost similar angular distance from first principle component axis are grouped together. Similarly, machines with almost similar angular distance are grouped together. Readers are advised to refer paper [25] for detailed description.

\subsection{Performance measurement}

Group efficiency (GE) does not represent true grouping performance for ordinal and ratio level data, since it treats all operation equally. Harhalakis et al. [6] proposed group technology efficiency (GTE), considering ordinal level data (i.e. sequence of operation). Grouping technology efficiency is given by Eq. (6):

$$
G T E=\left\{\left(I_{p}-I_{r}\right) / I_{p}\right\}
$$

and the number of intercell travels actually required by system:

$$
I_{r}=\sum_{J=1}^{p} \sum_{W(J)=1}^{(n(J)-1)} t_{n(J) W(J)}
$$

where: $p=$ total number of parts in system (i.e. CF problem),

$J=J^{\text {th }}$ part in system (i.e. CF problem),

$n(Z)=$ maximum number of operation required for $J^{\text {th }}$ part,

$t_{n(j) w(J)}=0$, if operation $W(J)$ and $W(J+1)$ are performed in same cell,

$=1$, otherwise.

Maximum numbers of intercell travel possible in system:

$$
I_{p}=\sum_{k=1}^{\text {nopf }} \sum_{J=1}^{\text {noptk }(k)}[n(J, K)-1]
$$

where: nopf $=$ total number of part families or cells,

$n o p f k(k)=$ total number of parts in $K^{\text {th }}$ cell,

$J=$ part number in a cell,

$N(J, K)=$ maximum number of operations required by $J^{\text {th }}$ part in $K^{\text {th }}$ cell.

GTE does not involve ratio level data. Lokesh Kumar [25] proposed Ratio grouping efficiency $(R G E)$. It is given as ratio of Machine utilization net gain (MUNG) to sum of Machine utilization opportunity gain (MUOG), Intercell travel loss (ICTL) (i.e. value of exceptional elements) and void value (i.e. value of voids, $V V$ ).

Ratio grouping efficiency,

$$
\begin{aligned}
& R G E=\{(M U N G) /(M U O G+I C T L+V V)\} \\
& M U N G=M U O G-I C T L \\
& M U O G=\sum_{k=1}^{n o p f} \sum_{I=1}^{n o m c k(k)} \sum_{J=1}^{n p f k(k)}\left[N_{v}(I, J, K) \cdot P L M(I, J, K) \cdot P V(1, J, K)\right] \\
& V V=\sum_{k=1}^{\text {nopf nomck }} \sum_{I=1}^{\text {no }} \sum_{J=1}^{n p f k(k)}\left[N_{v}(I, J, K) \cdot P L M(I, J, K) \cdot P V(1, J, K) / W_{p} f k(k)\right]
\end{aligned}
$$

where: $\operatorname{nom} c k(k)=$ number of machines in $K^{\text {th }}$ cell,

$N_{v}(I, J, K)=0$, if $I^{\text {th }}$ machine, $J^{\text {th }}$ part in cell $K$ has occupied elements,

$=1$, if $I^{\text {th }}$ machine, $J^{\text {th }}$ part in cell $K$ is a vacant element,

$\operatorname{PLM}(I, J, K)=$ operation time of $I^{\text {th }}$ machine for $J^{\text {th }}$ part in $K^{\text {th }}$ cell,

$P V(I, J, K)=$ production volume of $I^{\text {th }}$ part in $k^{\text {th }}$ cell,

$$
I C T L=\sum_{I_{1}=1}^{n_{e}}\left[t_{h}\left(I_{1}, J_{e}\right) \cdot P V\left(1, J_{e}\right)+t_{c c}\left(J_{e}\right)\right]
$$


where: $n_{e}=$ number of exceptional elements,

$P V(1, J)=$ Part Production volume of $J_{e}^{\text {th }}$ exceptional part,

$t_{h}\left(I_{1}, J\right)=$ Handling time for $J_{e}^{\text {th }}$ exceptional part,

$t_{c c}\left(J_{e}\right)=$ Transportation time for $J_{e}^{t h}$ exceptional part,

Setuptime $(I, J, K)=$ setup time for $I^{\text {th }}$ machine, $J^{\text {th }}$ part in $K^{\text {th }}$ cell

(one can also take load/unload and other idle times in account) [25].

Integrating ordinal level and ratio level data, a general model of performance measure is proposed: Weighted sequence ratio efficiency (WSRE). It is represented by Eq. (14):

$$
W S R E=\alpha \cdot R G E+(1-\alpha) \cdot G T E
$$

where $\alpha$ is a constant ranging from zero to one [25]. Nair \& Narendran and George et al. have taken objectives as minimum within-cell-load variation, minimum intercell travel volume and combined objective function of these two conflicting objectives, with ordinal level data and ratio level data. Readers are advised to refer papers $[14,15,16]$ for detailed description. It is extremely difficult to provide detailed description here due to length of paper constraint.

\section{APMOSTVC}

An algorithm for Concurrent part families and machine groups formation (Step-by-step procedure):

Step 1 - Matrix representation of data for input:

(a) Create Machine Sequence Part Matrix (MSPM) according to section 3.1 - I.

(b) Create Machine Part Operation time Matrix (MPOTM) according to section 3.1 - II.

(c) Create Production Volume Matrix, $P V$, Machine Capacity Matrix, $M C$, and set-up time Matrix, Setime, as described in section 3.1 - III, IV and V, respectively.

Step 2 - Create Part Load Matrix according to section 3.2 as:

(a) If operation time is given only:

$\operatorname{PLM}(I, J)=\operatorname{MPOTM}(I, J)$

(b) If operation time and production volume is given: $P L M(I, J)=\operatorname{MPOTM}(I, J) \times P V(1, J)$

(c) If operation time, production volume and machine capacity is given: $\operatorname{PLM}(I, J)=[\operatorname{MPOTM}(I, J) \times P V(1, J) / M C(I, J)]$

Step 3 - Create Sequence Part Load Matrix, SPLM according to section 3.3 as: $\operatorname{SPLM}(I, J)=\operatorname{MSPM}(I, J) \times P L M(I, J)$

Step 4 - Create standardized sequence Part Load Matrix SSPLM, as described in 3.4 - I.

Step 5 - From Part Part correlation Matrix, PPCM as described in section 3.4 - II.

Step 6 - Determine principle components (i.e. eigen vectors and eigen values) of PPCM matrix as described in section 3.4 - III.

Step 7 - Make feature vector i.e. take first two principle components (eigen vectors) and form a matrix with these eigen vectors in columns, described in section 3.4 - IV as follows: Feature Vector $=\left(F_{1}, F_{2}\right)$

Step 8 - Determine New Standardized Sequence Part Load Matrix, NSSPLM as described in section $3.4-$ V. NSSPLM is a vector product of transpose of Feature Vector and transpose of SSPLM.

Step 9 - Do Machine-part orthographic view cluster analysis as described in section 3.4 - VI.

Step 10 - Compute performance measures i.e. GTE, RGE, WRSE etc. 


\section{RESULT AND DISCUSSION}

We consider a problem (AI.C.A.) of size 12 parts $\times 10$ machines. It is considered by George et al. [14]. We also consider 0.1 minutes for loading/unloading and transportation time for AGV's from one cell to another cell. Table I represent machine-part matrix. It represents ordinal level data (i.e. sequence) and ratio level data (i.e. ratio of product of operation time and production volume to machine capacity). From this, sequence part load matrix, SPLM by using Eq. (1) is formed. Now, Standardized Sequence Part load matrix, SSPLM by using Eq. (2) is formed from SPLM. Next, Part - Part correlation matrix, PPCM by using Eq. (3) is formed from matrix SSPLM. Now, PPCM matrix is undergone through principle components analysis as described in section 3.4 - III. Here, we got principle component (PCA) matrix. First two principle components i.e. first and second column of $P C A$ matrix are used for grouping purpose. Feature-Vector i.e. Eq. (4) is created taking first two principle components i.e. first and second column of PCA matrix.

Now, new standardized sequence part load matrix, NSSPLM by using Eq. (5) is formed from Feature-Vector. Next, parts using Feature-Vector matrix and machines using NSSPLM matrix is drawn on Machine-Part Orthographic View as described in sections 3.4 - IV and 3.4 - VI, respectively. Finally, parts and machine represented on Machine-Part Orthographic View are shown in Fig. 1. Part families and machine groups are represented by Table I. Part family-1 has parts $\mathrm{p} 1, \mathrm{p} 5, \mathrm{p} 9$ and $\mathrm{p} 10$. It belongs to machine group- 1 with $\mathrm{m} 1, \mathrm{~m} 3, \mathrm{~m} 4, \mathrm{~m} 6$ and m8. Part family-2 has parts p2, p3, p7, p8 and p12. It belongs to machine group-2 with machines $\mathrm{m} 2, \mathrm{~m} 5$ and $\mathrm{m} 10$. Part family-3 has parts $\mathrm{p} 4, \mathrm{p} 6$ and $\mathrm{p} 11$. It belongs to machine group-3 with machines $\mathrm{m} 7$ and $\mathrm{m} 9$. This solution is the same configuration as proposed by George et al. Results of this problem are shown in Table III. Exceptional elements are 5. Grouping Efficiency is 85.00. Group Technology Efficiency is 80. Ratio Grouping Efficiency is 81.16. Weighted Sequence Ratio Efficiency is 80.58. Combined objective function is 0.610.

Next, a problem (ACCORD) [16] of size 10 parts $\times 8$ machines is considered. This problem is considered by Nair \& Narendran. The Machine-Part Orthographic View is shown in Fig. 2. Part families and machine groups are represented by Table II. Part family-1 has parts $\mathrm{p} 3, \mathrm{p} 8, \mathrm{p} 10$. It belongs to machine group- 1 with machines $\mathrm{m} 1$ and $\mathrm{m} 8$. Part family- 2 has parts $\mathrm{p} 2, \mathrm{p} 4$ and $\mathrm{p} 6$. It belongs to machine group-2 with machines $\mathrm{m} 4, \mathrm{~m} 5$ and $\mathrm{m} 7$. Part family-3 has parts p1, p5, p7 and p9. It belongs to machine group-3 with machines $\mathrm{m} 2, \mathrm{~m} 3$ and m6. Part families and machine groups formed, here, are the same as given by Nair \& Narenderan. Number of intercell travels, combined objective function, GTE etc. are shown by Table III.

Further, the problems of other sizes from open literature [26, 37, 38, etc.] are also considered. The real valued matrix is produced by assigning random numbers in the range of 0.5 to 1 as uniformly distributed values by replacing the ones / zeros in the incidence matrix. Processing times, sequence number and unit demands were randomly generated. For each machine type required by each part, a sequence number was generated using a uniform distribution with parameters $[1,10]$ rounded to the nearest integer. For each machine type required by each part, a processing time was generated using a uniform distribution with parameters [1, 10] rounded to the nearest integer. The unit demand for each part was generated using a uniform distribution with parameters [10,140] rounded to the nearest integer. Results on test data sets are shown by Table IV.

It is observed that the proposed algorithm APMOSTVC yields solution of good and comparable quality in its class [14, 16]. Research papers [15, 16] are important benchmark papers in area of CMS design. These are referred by many researchers. For instance, even Seifoddini has considered machine sequence and production volume only in 2007 [25]. Seifoddini [22, 24, 39] published several papers on CMS design as early as 1986 [39]. 
Table I: Output Machine Sequence Part Matrix (12×10), MSPM.

\begin{tabular}{|c|c|c|c|c|c|c|c|c|c|c|c|c|c|}
\hline \multicolumn{2}{|r|}{ Parts $\rightarrow$} & \multirow[t]{2}{*}{ p1 } & \multirow[t]{2}{*}{ P5 } & \multirow[t]{2}{*}{ p9 } & \multirow[t]{2}{*}{ p10 } & \multirow[t]{2}{*}{ p2 } & \multirow[t]{2}{*}{ p3 } & \multirow[t]{2}{*}{ p7 } & \multirow[t]{2}{*}{ p8 } & \multirow[t]{2}{*}{ p12 } & \multirow[t]{2}{*}{ P4 } & \multirow[t]{2}{*}{ p6 } & \multirow[t]{2}{*}{ p11 } \\
\hline $\mathbf{M c} \downarrow$ & OS/OT & & & & & & & & & & & & \\
\hline \multirow[t]{2}{*}{ M1 } & OS & 0 & 3 & 4 & 3 & 0 & 0 & 0 & 0 & 0 & 0 & 0 & 0 \\
\hline & OT & 0 & 0.63 & 0.54 & 0.39 & 0 & 0 & 0 & 0 & 0 & 0 & 0 & 0 \\
\hline \multirow[t]{2}{*}{ SPLMm3 } & OS & 1 & 5 & 1 & 1 & 0 & 0 & 0 & 0 & 0 & 0 & 0 & 0 \\
\hline & OT & 0.96 & 0.97 & $\begin{array}{|ll|}0 & .92 \\
\end{array}$ & 0.61 & 0 & 0 & 0 & 0 & 0 & 0 & 0 & 0 \\
\hline \multirow[t]{2}{*}{ M4 } & OS & 2 & 4 & \begin{tabular}{l|l}
0 \\
0
\end{tabular} & 0 & 0 & 0 & 0 & 0 & 0 & 1 & 1 & 0 \\
\hline & OT & 0.95 & 0.89 & 0 & 0 & 0 & 0 & 0 & 0 & 0 & 0.07 & 0.11 & 0 \\
\hline \multirow[t]{2}{*}{ M6 } & OS & \begin{tabular}{l|}
3 \\
\end{tabular} & 1 & 2 & 2 & 0 & 0 & 0 & 0 & 0 & \begin{tabular}{l|l}
0 \\
\end{tabular} & 0 & 0 \\
\hline & OT & 0.63 & 0.61 & 0.72 & 0.72 & 0 & 0 & 0 & 0 & 0 & 0 & 0 & 0 \\
\hline \multirow[t]{2}{*}{ M8 } & OS & 0 & 2 & 3 & 0 & 4 & 1 & 0 & 0 & 1 & 0 & 0 & 0 \\
\hline & OT & 0 & 0.94 & 0.92 & 0 & 0.04 & .08 & 0 & 0 & \begin{tabular}{l|l|}
0.02 \\
\end{tabular} & 0 & 0 & 0 \\
\hline \multirow[t]{2}{*}{ M2 } & OS & 0 & 0 & 0 & 0 & 1 & 2 & 1 & 1 & 3 & 0 & 0 & 0 \\
\hline & OT & 0 & 0 & 0 & 0 & 0.86 & 0.88 & 1.2 & 1.0 & 0.7 & 0 & 0 & 0 \\
\hline \multirow[t]{2}{*}{ M5 } & OS & 0 & 0 & 0 & 0 & 3 & 4 & 3 & 0 & 2 & 0 & 0 & 0 \\
\hline & OT & 0 & 0 & 0 & 0 & 0.54 & 0.49 & 0.81 & 0 & 0.72 & 0 & 0 & 0 \\
\hline \multirow[t]{2}{*}{ M10 } & OS & 0 & 0 & 0 & 0 & 2 & 3 & 2 & 2 & 0 & 0 & 0 & 0 \\
\hline & OT & 0 & 0 & 0 & 0 & 0.67 & 0.73 & \begin{tabular}{|l|}
0.83 \\
\end{tabular} & \begin{tabular}{l|}
0.62 \\
\end{tabular} & 0 & 0 & 0 & 0 \\
\hline \multirow[t]{2}{*}{ M7 } & OS & 0 & 0 & 0 & 0 & 0 & 0 & \begin{tabular}{l|}
0 \\
\end{tabular} & 0 & 0 & 3 & 3 & 1 \\
\hline & OT & 0 & 0 & 0 & 0 & 0 & 0 & 0 & 0 & 0 & \begin{tabular}{l|}
0.83 \\
\end{tabular} & 0.99 & 0.77 \\
\hline \multirow[t]{2}{*}{ M9 } & OS & 0 & 0 & 0 & 0 & 0 & 0 & 0 & 0 & 0 & 2 & 2 & 0 \\
\hline & OT & 0 & 0 & 0 & 0 & 0 & 0 & 0 & 0 & 0 & 0.72 & 0.76 & 0 \\
\hline \multicolumn{2}{|l|}{$P V$} & 12 & 40 & 45 & 80 & 75 & 120 & 150 & 75 & 110 & 60 & 90 & 25 \\
\hline \multicolumn{2}{|l|}{ Setime } & 0.5 & 1.0 & 1.4 & 0.8 & 0.75 & 1.25 & 0.66 & 1.5 & $\begin{array}{l}1.75 \\
\end{array}$ & 0.92 & .33 & 0.6 \\
\hline
\end{tabular}

Table II: Output Machine Sequence Part Matrix, MSPM $(10 \times 8)$.

\begin{tabular}{|c|c|c|c|c|c|c|c|c|c|c|c|}
\hline \multicolumn{2}{|c|}{ Parts $\rightarrow$} & \multirow[t]{2}{*}{ p1 } & \multirow[t]{2}{*}{ p5 } & \multirow[t]{2}{*}{ p7 } & \multirow[t]{2}{*}{ p9 } & \multirow[t]{2}{*}{ p2 } & \multirow[t]{2}{*}{ P4 } & \multirow[t]{2}{*}{ p6 } & \multirow[t]{2}{*}{ p10 } & \multirow[t]{2}{*}{ p3 } & \multirow[t]{2}{*}{ p8 } \\
\hline $\mathbf{M c} \downarrow$ & $\begin{array}{l}\text { Sequence } \\
\text { /ratio }\end{array}$ & & & & & & & & & & \\
\hline \multirow[t]{2}{*}{ M2 } & Sequence & 3 & 3 & 2 & 1 & 0 & 0 & 0 & 5 & 0 & 0 \\
\hline & Ratio & 0.9 & 0.9 & 0.5 & 0.3 & 0 & 0 & 0 & 0.6 & 0 & 0 \\
\hline \multirow[t]{2}{*}{ M3 } & Sequence & 1 & 1 & 1 & 2 & 0 & 0 & 0 & 0 & 0 & 0 \\
\hline & Ratio & 0.9 & 0.9 & 0.5 & 0.3 & 0 & 0 & 0 & 0 & 0 & 0 \\
\hline \multirow[t]{2}{*}{ M7 } & Sequence & 2 & 2 & 0 & 0 & 0 & 1 & 1 & 0 & 0 & 0 \\
\hline & Ratio & 0.6 & 0.3 & 0 & 0 & 0 & 0.4 & 0.4 & 0 & 0 & 0 \\
\hline \multirow[t]{2}{*}{ M4 } & Sequence & 0 & 0 & 0 & 0 & 2 & 2 & 3 & 1 & 0 & 0 \\
\hline & Ratio & 0 & 0 & 0 & 0 & 0.8 & 0.8 & 0.8 & 0.6 & 0 & 0 \\
\hline \multirow[t]{2}{*}{ M5 } & Sequence & 0 & 0 & 0 & 0 & 3 & 3 & 2 & 0 & 0 & 0 \\
\hline & Ratio & 0 & 0 & 0 & 0 & 0.8 & 0.8 & 0.8 & 0 & 0 & 0 \\
\hline \multirow[t]{2}{*}{ M6 } & Sequence & 0 & 0 & 0 & 0 & 4 & 0 & 4 & 2 & 3 & 3 \\
\hline & Ratio & 0 & 0 & 0 & 0 & 0.8 & 0 & 0.8 & 0.15 & 0.15 & 0.15 \\
\hline \multirow[t]{2}{*}{ M1 } & Sequence & 0 & 0 & 0 & 0 & 1 & 0 & 0 & 3 & 1 & 2 \\
\hline & Ratio & 0 & 0 & 0 & 0 & 0.4 & 0 & 0 & 0.6 & 0.6 & 0.6 \\
\hline \multirow[t]{2}{*}{ M8 } & Sequence & 0 & 0 & 0 & 0 & 0 & 0 & 0 & 4 & 2 & 1 \\
\hline & Ratio & 0 & 0 & 0 & 0 & 0 & 0 & 0 & 0.6 & 0.6 & 0.6 \\
\hline \multicolumn{2}{|l|}{$P V$} & 12 & 40 & 75 & 45 & 75 & 60 & 90 & 80 & 120 & 110 \\
\hline \multicolumn{2}{|c|}{ Setime } & 0.5 & 1.0 & 1.5 & 1.4 & 0.75 & 0.92 & 0.33 & 0.8 & 1.25 & 1.75 \\
\hline
\end{tabular}

Table III: Comparison of the results of the proposed method over existing methods for the problem of size $12 \times 10$ (AI.C.A.) and $10 \times 8$ (ACCORD).

\begin{tabular}{|l|l|c|c|c|c|}
\hline & Factors considered & ACCORD & APMOSTVC & AI.C.A. & APMOSTVC \\
\hline 1 & Problem size $(m \times p)$ & $10 \times 8$ & $10 \times 8$ & $12 \times 10$ & $12 \times 10$ \\
\hline 2 & Exceptional elements & 8 & 8 & 5 & 5 \\
\hline 3 & Grouping efficiency & 0.897 & 0.897 & 0.85 & 0.85 \\
\hline 4 & Group technology efficiency (\%) & 68.20 & 68.20 & 80.00 & 80.00 \\
\hline 5 & Ratio grouping efficiency (\%) & - & 80.58 & - & 81.16 \\
\hline 6 & Weighted sequence Ratio efficiencies & - & 72.24 & - & 80.58 \\
\hline 7 & Combined objective functions & 0.517 & 0.517 & 0.610 & 0.610 \\
\hline
\end{tabular}




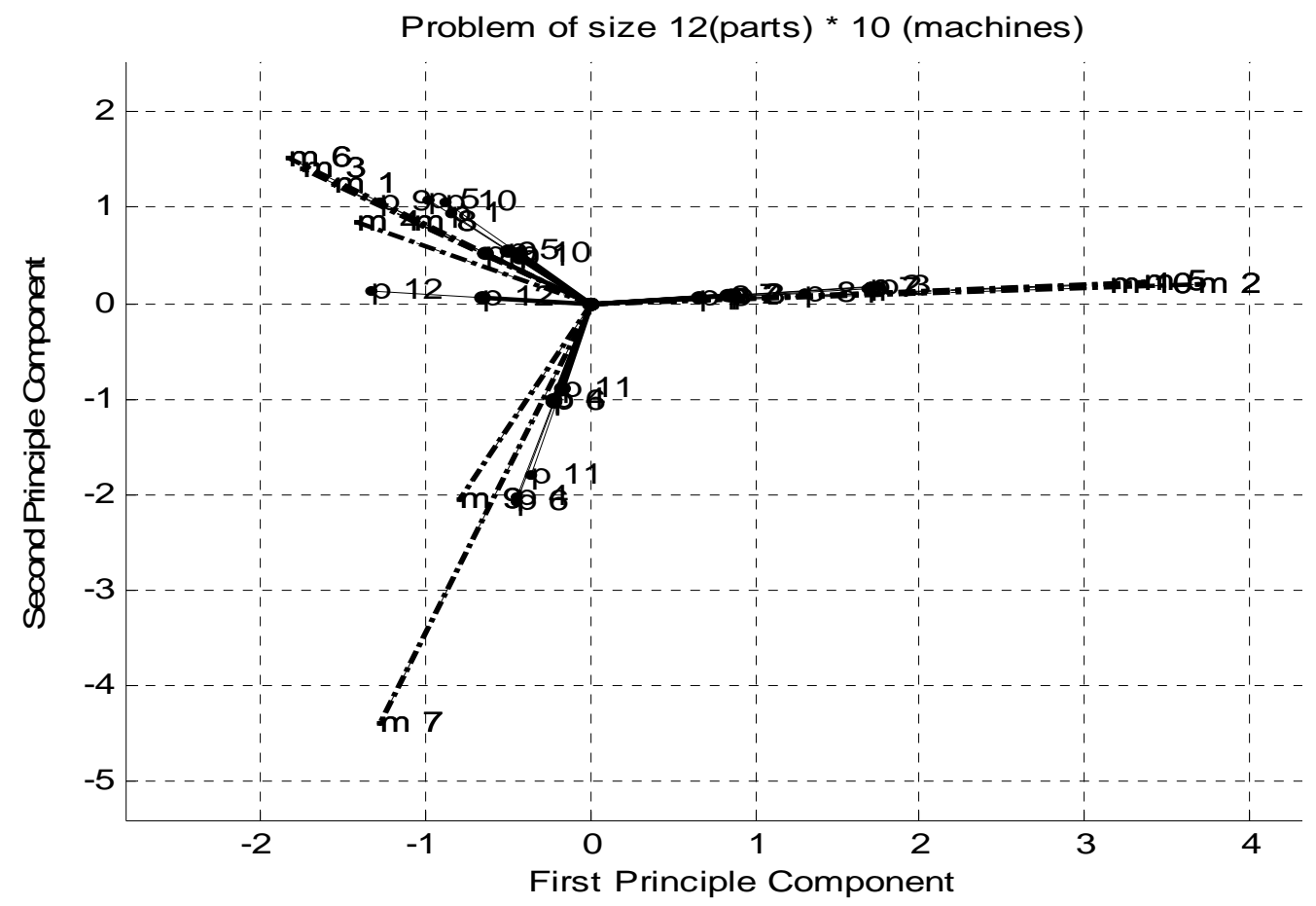

Figure 1: Orthographic View Part Grouping; problem 1: part machine $(p \times m)$ size $(10 \times 12)$.

Table IV: Algorithm performance on test Data set.

\begin{tabular}{|c|c|c|c|c|c|c|c|c|c|c|c|c|}
\hline \multirow[b]{3}{*}{ ż } & \multirow{2}{*}{\multicolumn{2}{|c|}{$\begin{array}{c}\text { Problem } \\
\text { Size }\end{array}$}} & \multicolumn{5}{|c|}{ APOSTVUIT } & \multicolumn{5}{|c|}{ APMOSTVC } \\
\hline & & & \multirow{2}{*}{ 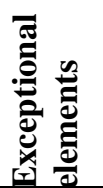 } & \multirow[b]{2}{*}{ 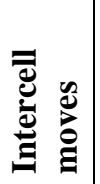 } & \multirow[b]{2}{*}{ 뇐 } & \multirow[b]{2}{*}{ 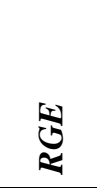 } & \multirow[b]{2}{*}{$\begin{array}{l}01 \\
0 \\
3\end{array}$} & \multirow{2}{*}{ 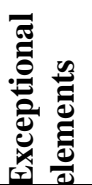 } & \multirow{2}{*}{ 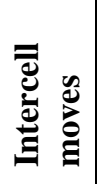 } & \multirow[b]{2}{*}{ 닌 } & \multirow[b]{2}{*}{ 눤 } & \multirow[b]{2}{*}{ 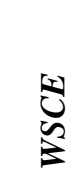 } \\
\hline & $\begin{array}{l}\dot{0}: \\
\dot{\vec{z}} \dot{\Xi}\end{array}$ & 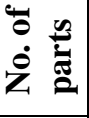 & & & & & & & & & & \\
\hline 1 & 4 & 5 & 0 & 0 & 100 & 85.48 & 92.74 & 0 & 0 & 100 & 85.48 & 92.74 \\
\hline 2 & 5 & 7 & 1 & 1 & 85.81 & 82.25 & 84.03 & 1 & 1 & 85.81 & 82.25 & 84.03 \\
\hline 3 & 5 & 8 & 6 & 5 & 64.30 & 80.17 & 72.24 & 6 & 5 & 64.30 & 80.17 & 72.24 \\
\hline 4 & 6 & 19 & 2 & 2 & 85.61 & 74.75 & 80.18 & 2 & 2 & 85.61 & 74.75 & 80.18 \\
\hline 5 & 12 & 20 & 8 & 8 & 83.93 & 73.29 & 78.61 & 8 & 8 & 83.93 & 73.29 & 78.61 \\
\hline 6 & 12 & 20 & 11 & 9 & 79.00 & 72.56 & 75.78 & 11 & 9 & 79.00 & 72.56 & 75.78 \\
\hline 7 & 20 & 20 & 3 & 3 & 94.5 & 87.86 & 91.18 & 3 & 3 & 94.5 & 87.86 & 91.18 \\
\hline 8 & 15 & 30 & 20 & 16 & 77.81 & 70.63 & 74.22 & 20 & 16 & 77.81 & 70.63 & 74.22 \\
\hline 9 & 20 & 37 & 24 & 24 & 72.50 & 70.10 & 71.30 & 24 & 24 & 72.50 & 70.10 & 71.30 \\
\hline 10 & 25 & 50 & 48 & 45 & 70.15 & 66.1 & 68.13 & 48 & 45 & 70.15 & 66.1 & 68.13 \\
\hline 11 & 20 & 55 & 14 & 18 & 82.30 & 73.90 & 78.10 & 14 & 18 & 82.30 & 73.90 & 78.10 \\
\hline 12 & 28 & 60 & 38 & 37 & 71.60 & 64.30 & 67.95 & 38 & 37 & 71.60 & 64.30 & 67.95 \\
\hline 13 & 30 & 65 & 57 & 50 & 77.88 & 68.48 & 73.18 & 57 & 50 & 77.88 & 68.48 & 73.18 \\
\hline 14 & 32 & 80 & 52 & 58 & 75.67 & 72.83 & 74.25 & 52 & 58 & 75.67 & 72.83 & 74.25 \\
\hline 15 & 35 & 90 & 53 & 55 & 78.89 & 71.43 & 75.16 & 53 & 55 & 78.89 & 71.43 & 75.16 \\
\hline
\end{tabular}

\section{CONCLUSION}

In his work, an algorithm, APMOSTVC is developed and proposed for Concurrent formation of part families and machine groups. Most of the existing methods are solely based on binary (i.e. 0,1) machine component incidence matrix only. But proposed algorithm is real-valued matrix based. A few researchers have employed either the operation sequence or a combination of processing time, total machine available time and volume of components, this paper considered all of these data concurrently. A matrix model is developed incorporating 
important manufacturing shop floor realities machine sequence, operation time, production volume and machine capacity. The model is analyzed using principle component analysis. Among several techniques, a few researchers used principle component analysis technique. Machine-Part groups are formed by using graphical grouping techniques. Part families and machine groups are also formed concurrently.

The algorithm yields good and comparable solutions in its class [14, 16, 25] in negligible computational time. Even Seifoddini has referred papers $[15,16]$ in his paper [22] in 2007. He has considered ordinal level data that is machine sequence and ratio level data as production volume only in his SCM model. However, he did not consider other important shop floor realities that are operation time and machine capacity in his SCM model.

Part families and machine groups evolve naturally. Algorithm gives flexibility to designer by removing constraint on number of cells and/ on number of cell to be decided in advance. Moreover, algorithm has very good industrial application potential. It is simple easy to understand and implement. It does not require skills of complex optimization techniques and programming. Algorithm APMOSTVC can be implemented using free software, Scilabplatform [40]. It is matrix based free software. The programming in Scilab is easy and very user friendly. Further, there are much expensive commercial software (SPSS, SAS, STAD, XLSTATS etc.) that can be used with APMOSTVC.

\section{REFERENCES}

[1] Adenso-Diaz, B.; Lozano, S.; Eguira, I. (2005). Part-machine grouping using weighted similarity coefficients, Computers \& Industrial Engineering, Vol. 48, 553-570

[2] Albadawi, Z.; Bashir, H. A.; Chen, M. (2005). A mathematical approach for the formation of Manufacturing cell, Computers \& Industrial Engineering, Vol. 48, 3-21

[3] Arvindh, B.; Irani, S. A. (1991). Principal components analysis for evaluating the feasibility of cellular manufacturing without initial-part matrix clustering, Int. J. of Production Research, Vol. 32, 1909-1938

[4] Cheng, C. H.; Goh, C. H.; Lee, A. (2001). Designing group technology manufacturing systems using heuristic branching rules, Computers \& Industrial engineering, Vol. 40, 117-131

[5] Genwook, J.; Leep, H. R.; Parsaaei, H. R. (1998). A cellular manufacturing system based on new similarity coefficient which considers alternative routes during machine failure, Computers \& Industrial engineering, Vol. 34, 21-36

[6] Harhalakis, G.; Nagi, R.; Proth, J. M. (1990). An efficient heuristic in manufacturing cell formation for group technology applications, Int. J. of Production Research, Vol. 28, No.1, 185198

[7] King, J. R.; Nakornchai, V. (1982). Machine-component group formation in group technology: review and extension, Int. J. of Production Research, Vol. 20, 117-133

[8] Kitaoka, M.; Nakamura, R.; Seriza, S.; Usuki, J. (1999). Multivariate analysis model for machine-part cell formation problem in GT, Int. Journal of Production Economics, Vol. 60-61, 433-438

[9] Srinivasan, G.; Narendran, T. T. (1991). GRAFICS: a nonhierarchical clustering algorithm for group technology, Int. J. of Production Research, Vol. 29, 463-478

[10] Stawowy, A. (2006). Evolutionary strategy for manufacturing cell design, The international Journal of Management Science: Omega, Vol. 34, 1-18

[11] Wang, J. (2003). Formation of machine cells and part families in cellular manufacturing systems using a linear assignment algorithm, Automatica, Vol. 39, 1607-1615

[12] Yasuda, K.; Yin, Y. (2001). A dissimilarity measure for solving the cell formation problem in cellular manufacturing, Computers \& Industrial Engineering, Vol. 39, 1-17

[13] Yin, Y.; Kazuhiko, K. (2006). Similarity coefficient methods applied to the cell formation problem: A taxonomy and review, Int. Journal of Production Economics, Vol. 101, 329-352 
[14] George, A. P.; Rajendran, C.; Ghosh, S. (2003). An analytical-iterative clustering algorithm for cell formation in cellular manufacturing systems with ordinal-level and ratio-level data. International Journal of Advanced Manufacturing Technology, Vol. 22, 125-133

[15] Nair, J. G.; Narendran, T. T. (1998). CASE: A clustering algorithm for cell formation with sequence data, Int. J. of Production Research, Vol. 36, No. 1, 157-179

[16] Nair, J. G.; Narendran, T. T. (1999). ACCORD: A bicriterion algorithm for cell formation using ordinal and ratio-level data, Int. J. of Production Research, Vol. 37, 539-556

[17] Suresh, N. C.; Slomp, J.; Kaparthi, S. (1999). Sequence-dependent clustering of parts and machines: a Fuzzy ART neural network approach, Int. J. of Production Research, Vol. 37, No. 12, 2793-2816

[18] Yin, Y.; Yasuda, K.; Kazuhiko, K. (2002). Manufacturing cells' design in consideration of various productions factors, Int. J. of Production Research, Vol. 40, No. 4, 885-906

[19] Jayaswal, S.; Adil, G. K. (2004). Efficient algorithm for cell formation with sequence data, machine replications and alternative process routings, Int. J. of Production Research, Vol. 42, No. 12, 2419-2433

[20] Wu, X.; Chu, C. H.; Wang, Y.; Yan, W. (2006). Concurrent design of cellular manufacturing systems: a genetic algorithm approach, Int. J. of Production Research, Vol. 44, No. 6, 1217-1241

[21] Won, Y.; Currie, K. R. (2007). Fuzzy ART/RRR-RSS: a two-phase neural network algorithm for part-machine grouping in CM, Int. J. of Production Research, Vol. 45, No. 9, 2073-2104

[22] Alhourani, F.; Seifoddini, H. (2007). Machine cell formation for production management in cellular manufacturing systems, Int. J. of Production Research, Vol. 45, No. 4, 913-934

[23] Miltenburg, J.; Montazemi, A. R. (1993). Revisiting the cell formation problem: assigning parts to production systems, Int. J. of Production Research, Vol. 31, No. 11, 2727-2746

[24] Seifoddini, H.; Tjahjana, B. (1999). Part-family formation for cellular manufacturing: a case study at Harnischfeger, Int. J. of Production Research, Vol. 37, No. 14, 3263-3273

[25] Lokesh, K.; Jain, P. K. (2008). Part-Machine Group Formation with Operation Sequence, Time and Production Volume, Int. J. of Simulation Modelling, Vol. 7, No. 4, 198-209

[26] Chandrasekharan, M. P; Rajagopalan, R. (1986). An ideal seed nonhierarchical clustering algorithm for cellular manufacturing, Int. J. of Production Research, Vol. 24, No. 2, 451-463

[27] Selim, H. M.; Askin, R. G.; Vakharia, A. J. (1998). Cell formation in-group technology: review, evaluation and direction for future research, Computers \& Industrial Engineering, Vol. 34, No. 1, 3-20

[28] Nash, J. F. (1950). The bargaining problem, Econometrica, Vol. 21, 155-162

[29] Panneerselvam, R. (2004). Research Methodology, $2^{\text {nd }}$ edition, Prentice Hall of India Pvt. Ltd., Delhi

[30] Kothari, C. R. (2004). Research Methodology, $2^{\text {nd }}$ edition, New Age Publisher Ltd., Delhi

[31] Gnanadesikan, R. (1997). Methods for Statistical Data Analysis of Multivariate observations, $3^{\text {rd }}$ edition, Wiley, New York, 7-15

[32] Rummel, R. J. (1988). Applied factor analysis, $1^{\text {st }}$ edition, Evanston: Northwestern University Press

[33] Jolliffe, I. T. (2002). Principal component analysis, $2^{\text {nd }}$ edition, Springer-Verlag, New York

[34] Howard, A. (1998). Elementary Linear Algebra, Fifth edition, John Willy and Sons Inc.

[35] Gonzalez, R. C.; Wintz, P. (1987). Digital Image Processing, $2^{\text {nd }}$ edition, Addison-Wesley Publishing Company, New York

[36] Kusiak, A.; Wang, J. (1993). Efficient organizing of design activities, Int. J. of Production Research, Vol. 31, No. 4, 753-769

[37] Boctor, F. F. (1991). A linear formulation of the machine-part cell formation problem, Int. J. of Production Research, Vol. 29, No. 2, 343-356

[38] Venugopal, V.; Narendran, T. T. (1992). A genetic algorithm approach to the machine component grouping prob. with multiple objectives, Computers \& Industrial Engineering, Vol. 22, 469-480

[39] Seifoddini, H.; Wolfe, P. M. (1986). Application of similarity coefficient method in GT, IIE Transactions, Vol. 21, 382-388

[40] Scilab: Platform - Scilab.org/Platform 